\title{
3. Endogenous strategic issue linkage in international negotiations
}

\section{Carlo Carraro and Carmen Marchiori}

\section{INTRODUCTION}

In recent years, the non-cooperative approach to coalition formation has been adopted to analyse various economic problems (cf. Bloch, 1997; Carraro and Marchiori, 2002; Konishi et al., 1997; Ray and Vohra, 1996, 1997; Yi, 1997). When applying theoretical results on coalition formation to the provision of public goods - and in particular to global environmental agreements - the conclusion is often that no coalition forms at the equilibrium and that, if a non-trivial equilibrium coalition emerges, it is formed by a small number of players (Hoel, 1991, 1992; Carraro and Siniscalco, 1993; Barrett, 1994, 1997; Heal, 1994). This result is the consequence of the presence of strong free-riding incentives that become even stronger in the presence of leakage (that is, when reaction functions are non-orthogonal; cf. Carraro and Siniscalco, 1993).

Different policy strategies have been proposed to increase the number of players who decide to join the equilibrium coalition. Transfers and issue linkage are probably the most popular proposed strategies, even though negotiation rules and treaty design can also be used to achieve equilibria in which large-sized coalitions form at the equilibrium (cf. Carraro, 2001).

In this chapter, we focus on issue linkage. The basic idea of issue linkage is to design a negotiation framework in which countries do not negotiate only on one issue (for instance, the environmental issue), but force themselves to negotiate on two joint issues (for example, the environmental and another interrelated economic issue).

Pioneering contributions on issue linkage are those by Tollison and Willett (1979) and Sebenius (1983). They propose this mechanism to promote cooperation not only on environmental matters, but also on other issues, for example, security and international finance. They also emphasise the increase in transaction costs that can result from the use of issue linkage.

Issue linkage was introduced into the economic literature on international environmental cooperation by Folmer et al. (1993) and by Cesar and 
De Zeeuw (1996) to solve the problem of asymmetries among countries. The intuition is simple: if some countries gain from cooperating on a given economic issue whereas other countries gain from cooperating on another, by linking the two issues it may be possible to obtain an agreement that is profitable to all countries.

Issue linkage can also be used to mitigate the problem of free-riding. To do this, negotiations that are affected by free-riding - that is, negotiations concerning public goods - must be linked with negotiations on club or quasi-club goods. The intuition is that the incentives to free-ride on the non-excludable benefits of public good provision can be offset by the incentives to appropriate the excludable benefits coming from providing the club good.

To address the free-riding problem, Barrett $(1995,1997)$ proposes linking environmental protection to negotiations on trade liberalisation. In this way, potential free-riders are deterred with threats of trade sanctions. In Carraro and Siniscalco (1995, 1997) and Katsoulacos (1997), environmental cooperation is linked to cooperation in research and development (R\&D). If a country does not cooperate on the control of the environment, it loses the benefits of technological cooperation. An empirical analysis of this type of issue linkage in the case of climate negotiations is contained in Buchner et al. (2002). Finally, Mohr (1995) and Mohr and Thomas (1998) propose linking climate negotiations to international debt swaps.

These contributions show the effectiveness of linkage in increasing the equilibrium number of cooperators on the provision of public goods, but do not investigate the forces which determine the number of issues which could be optimally linked and the related size of the equilibrium coalition (that is, the number of players/countries who cooperate on the linked issues). In a recent work, Alesina et al. (2001) extend the analysis of the effectiveness of issue linkage to the case of heterogeneous countries. One of the most interesting results of their paper is the identification of a trade-off between the size and the scope of a coalition: a coalition where countries cooperate on too many issues may be formed by a few countries, which implies small spillovers among them, whereas coalitions in which cooperation is restricted to few issues may be joined by many countries, thus raising many positive externalities within the coalition. However, the work by Alesina et al. (2001) assumes away the existence of free-riding incentives, which are instead one of the crucial features of the game analysed in this chapter.

In this chapter, we focus on coalitions which can cooperate on at most two issues. The goal of this chapter is neither to check the effectiveness of issue linkage in increasing the number of cooperating countries, nor to identify the number of economic issues that can be optimally linked. 
Instead, the goal here is to analyse whether issue linkage belongs to the equilibrium of the game when issue linkage is not exogenously assumed, but players can decide whether or not to link two economic issues on which they know they will have to negotiate.

Let us consider an example. In the case of global environmental issues, incentives to free-ride on emission abatement are strong and cooperation is unlikely. In addition, there is no supra-national authority that can impose the adoption of issue linkage. Negotiating countries therefore decide independently whether or not to link the negotiation on a global environmental problem to the negotiation on a different economic issue. This decision is a strategic choice that players make. A game therefore describes the incentives to link the two issues. This game is also characterised by freeriding incentives. The reason for this is that issue linkage may indeed increase the number of cooperators on the provision of a global environmental good; however, at the same time, issue linkage may reduce the number of cooperators on the second issue (the one linked to the provision of the global environmental good). Hence, even if issue linkage increases the number of signatories - and therefore the amount of global environmental good provided - it may not be an equilibrium outcome.

The crucial question is therefore the following: do players have an incentive to link the negotiations on two different issues instead of negotiating on the two issues separately? Is the choice of issue linkage an equilibrium of the game in which players decide non-cooperatively whether or not to link the negotiations on two different economic issues?

This chapter answers the above questions by analysing a three-stage noncooperative sequential game. In the first stage, players decide whether or not to link the negotiations on two issues on which they are trying to reach an agreement. If they decide not to link the two issues, in the second stage they decide whether or not to sign either one or both separate agreements. If they decide in favour of issue linkage, in the second stage they decide whether or not to sign the linked agreement. Finally, in the third stage they set the value of their policy variables.

When analysing this game, two cases will be considered: one in which the benefits accruing to the signatories of one of the two separate agreements are perfectly or almost perfectly excludable (cooperators provide a club good), and one in which the degree of excludability is low.

Let us underline that the decision taken in the first stage of the game is analysed assuming the unanimity voting rule. Indeed, the choice of issue linkage can be considered as a negotiation rule whose determination precedes the beginning of actual negotiations and which therefore should be taken with the consensus of all countries involved in the negotiation process. However, the extension to the case of majority voting is straightforward. 
The structure of the chapter is as follows. Section 2 introduces the basic definitions and assumptions. Section 3 describes the different cases in which the game will be solved. Section 4 presents the equilibrium of the threestage game under different degrees of excludability of the club good. Finally, Section 5 discusses the main conclusions of our analysis, possible extensions, and policy implications.

\section{DEFINITIONS AND ASSUMPTIONS}

Assume $n$ players face the following situation: they decide to either link the two negotiations or not to link them. If the two negotiations are not linked, they subsequently decide whether or not to participate in the first agreement, or in the second agreement, or in both. If the two negotiations are linked, they then decide whether or not to sign the linked agreement.

The game therefore has three stages. In the first stage, the linkage game takes place, where the $n$ players decide simultaneously and noncooperatively whether or not to introduce a rule that forces all players to negotiate on a single agreement in which the two issues are linked. In the second stage, the coalition game, they decide simultaneously and noncooperatively whether or not to sign one of the available treaties (that is, to join a coalition $c$ of cooperating countries). In the third stage, they play the non-cooperative Nash policy game, where players that signed the agreement play as a single player and divide the resulting payoff according to a given burden-sharing rule (any of the rules derived from cooperative game theory).

A few assumptions are necessary to simplify our analysis.

A.1 (Uniqueness): The third stage game, the policy game, in which all players decide simultaneously, has a unique Nash equilibrium for any coalition structure. ${ }^{1}$

A.2 (Cooperation): Inside each coalition, players act cooperatively in order to maximise the coalitional surplus, whereas coalitions (and singletons) compete with one another in a non-cooperative way.

A.3 (Symmetry): All players are ex-ante identical, which means that each player has the same strategy space in the second stage game.

Assumption A.3 allows us to adopt an equal sharing payoff division rule inside any coalition, that is, each player in a given coalition receives the same payoff as the other members of the coalition. Furthermore, the sym- 
metry assumption implies that a coalition can be identified with its size $c$. As a consequence, the payoff received by the players only depends on the coalition sizes and not on the identity of the coalition members.

Given the above assumptions, a per-member partition function (partition function hereafter) can be defined. It can be denoted by $p(c ; \pi)$, which represents the payoff of a player belonging to the size- $c$ coalition in the coalition structure $\pi$. Let $\pi=\left\{\alpha_{(r)}, \beta_{(s)}, \ldots\right\}$ be a coalition structure formed by $r$ size- $\alpha$ coalitions, $s$ size- $\beta$ coalitions, etc.

A.4 (Issues): Negotiations take place on two, exogenously given, issues (called ' $a$ ' and ' $t$ ' in this chapter). Therefore, there is no trade-off between the size and scope of a coalition.

A.5 (Single coalition): Players are proposed to sign a single agreement. Hence, those who do not sign the agreement cannot propose a different one. From a game-theoretic viewpoint, this implies that only one coalition can be formed, the defecting players playing as singletons. Hence $\pi=\left\{c, 1_{(n-c)}\right\}$, where $1_{\{n-c\}}$ denotes the $n-c$ singletons, and the partition (payoff) function can simply be denoted by $P(c)$.

A.6 (Open Membership): Each player is free to join and to leave the coalition without the consensus of the other coalition members.

This assumption enables us to adopt the usual Nash equilibrium concept to identify the equilibrium of the coalition game. Different results could be obtained under exclusive membership or coalition unanimity (cf. Carraro and Marchiori, 2002).

Let us introduce a few definitions. Let $c_{u}^{*}$ denote the equilibrium number of players who sign the linked agreement (that is, when issue linkage is chosen in the first stage of the game). Then $P_{u}\left(c_{u}^{*}\right)$ is their equilibrium payoff. The remaining $n-c_{u}^{*}$ players are the free-riders of the linked agreement. Their equilibrium payoff is $Q_{u}\left(c_{u}^{*}\right)$.

If linkage is not adopted, we have two agreements. Let ' $a$ ' identify the agreement whose benefits are not excludable (for instance, the environmental agreement), whereas ' $t$ ' identifies the agreement with (partly) excludable benefits (for example, the agreement on technological cooperation). Then, let $c_{a}^{*}$ be the equilibrium number of players who sign the public good agreement, or ' $a$-agreement', whereas $c_{t}^{*}$ is the equilibrium number of signatories of the (quasi) club good agreement, or ' $t$-agreement'. $P_{a}\left(c_{a}^{*}\right)$ is the equilibrium payoff of the former, whereas $P_{t}\left(c_{t}^{*}\right)$ is the equilibrium payoff of the latter. Finally, free-riders of the ' $a$-agreement' obtain a payoff equal to $Q_{a}\left(c_{a}^{*}\right)$, whereas free-riders of the ' $t$-agreement' obtain $Q_{t}\left(c_{t}^{*}\right)$. 
These definitions enable us to introduce another useful assumption:

A.7 (Additivity): $\quad P_{u}(c)=P_{a}(c)+P_{t}(c), \forall c$ and $Q_{u}(c)=Q_{a}(c)+Q_{t}(c), \forall c$. Hence, the payoff that can be obtained from linking the two agreements is equal to the sum of the payoffs of the two individual agreements, both for cooperators in the joint agreement and for its free-riders.

Finally, under open membership (Assumption A.6), the following equilibrium concept is adopted:

Equilibrium: A coalition $c^{*}$ is an equilibrium coalition if it is profitable and stable, where profitability and stability are defined as follows:

Profitability: A coalition $c^{*}$ is profitable if each cooperating player gets a larger payoff than the one he would get when no coalition forms. Formally:

$$
P\left(c^{*}\right) \geq P(0)
$$

for all players in the coalition $c^{*}, 2 \leq c^{*} \leq n .^{2}$

Stability: A coalition formed by $c^{*}$ players is stable if on the one hand there is no incentive to free-ride, that is:

$$
Q\left(c^{*}-1\right)-P\left(c^{*}\right) \leq 0
$$

and on the other hand there is no incentive to broaden the coalition, that is:

$$
P\left(c^{*}+1\right)-Q\left(c^{*}\right)<0
$$

Notice that, if a coalition $c^{*}$ is profitable and stable, then no player has an incentive to modify his decision to sign or not to sign the agreement. Hence, $c^{*}, 2 \leq c^{*} \leq n$, is the outcome of a Nash equilibrium in which each country's strategy set is $\{$ sign, not sign $\}$.

In particular, $c_{u}^{*}$ identifies the size of the equilibrium coalition when issue linkage is adopted iff:

$$
\begin{gathered}
P_{a}\left(c_{u}^{*}\right)+P_{t}\left(c_{u}^{*}\right) \geq P_{a}(0)+P_{t}(0) \\
P_{a}\left(c_{u}^{*}\right)+P_{t}\left(c_{u}^{*}\right) \geq Q_{a}\left(c_{u}^{*}-1\right)+Q_{t}\left(c_{u}^{*}-1\right) \\
P_{a}\left(c_{u}^{*}+1\right)+P_{t}\left(c_{u}^{*}+1\right)<Q_{a}\left(c_{u}^{*}\right)+Q_{t}\left(c_{u}^{*}\right)
\end{gathered}
$$

From (3.3a) it is clear that, if the two separate agreements are profitable, then the linked agreement is also profitable. However, a linked agreement 
may be profitable to all players even when the two separate agreements are profitable only to a fraction of the $n$ players of the game (two different fractions for the two agreements). This is why, as explained in the introduction to this chapter, issue linkage has been proposed to solve the profitability problem (cf. Cesar and De Zeeuw, 1996).

Let us define the structure and the payoffs of the linkage game. If players decide to link the two issues and negotiate on a joint agreement, the equilibrium payoffs are:

$$
P_{u}\left(c_{u}^{*}\right)=P_{a}\left(c_{u}^{*}\right)+P_{t}\left(c_{u}^{*}\right)
$$

for a signatory of the agreement;

$$
Q_{u}\left(c_{u}^{*}\right)=Q_{a}\left(c_{u}^{*}\right)+Q_{t}\left(c_{u}^{*}\right)
$$

for a free-rider.

If instead players prefer not to link the two issues, they decide whether or not to participate in two different agreements. In this case, at the equilibrium they obtain the following payoffs:

$$
P_{a}\left(c_{a}^{*}\right)+P_{t}\left(c_{t}^{*}\right)
$$

if they decide to cooperate on both issues;

$$
P_{a}\left(c_{a}^{*}\right)+Q_{t}\left(c_{t}^{*}\right)
$$

if they cooperate in the 'a-agreement', but they free-ride on the 't-agreement';

$$
Q_{a}\left(c_{a}^{*}\right)+P_{t}\left(c_{t}^{*}\right)
$$

if they cooperate in the ' $t$-agreement', but free-ride on the other issue;

$$
Q_{a}\left(c_{a}^{*}\right)+Q_{t}\left(c_{t}^{*}\right)
$$

if they free-ride on both issues. Hence, without linkage, there are four 'types' of countries, where the identity of the countries is irrelevant because of symmetry. The structure of the game and its payoffs are summarised in Figure 3.1.

Let us make two final assumptions on how decisions are taken in the first stage of the game. 


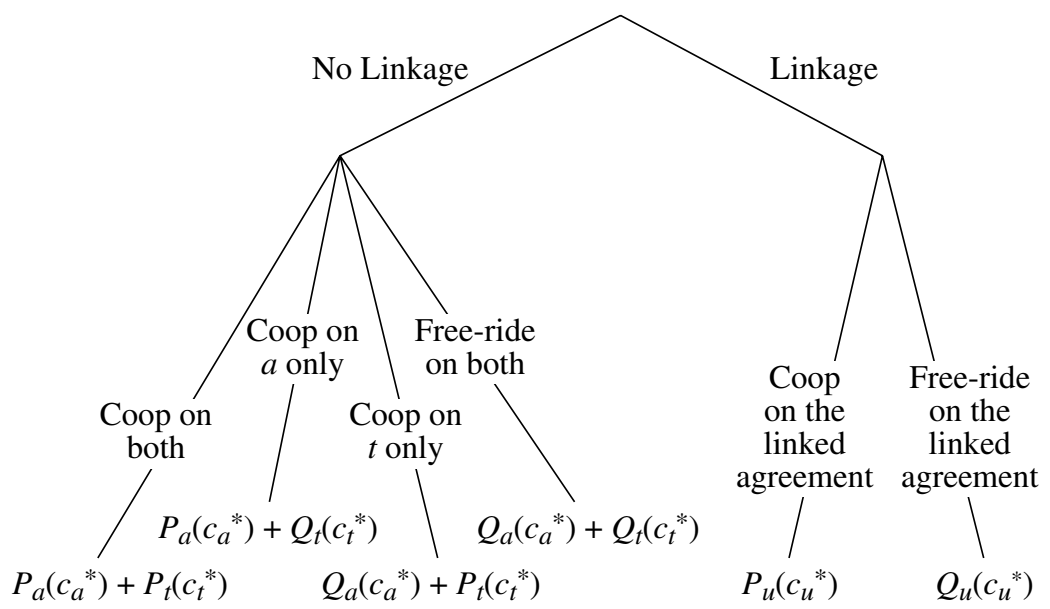

Figure 3.1 The structure of the game

A.8 (Voting): In the first stage of the game, decisions are taken by unanimous agreement (players set a sort of constitutional rule). ${ }^{3}$

A.9 (Max-min strategy): In the first stage of the game, a player selects issue linkage only when the worst payoff this choice provides is larger that the one he would get without linkage under any strategy in the second stage of the game (cooperator or non-cooperator, on one issue or two issues).

The idea is that a player votes in favour of linkage only if the worst payoff he gets when the issues are linked is larger than the best payoff he can obtain in the absence of linkage. The equilibrium conditions of the linkage game are then easily obtained by comparing the payoffs summarised in Figure 3.1.

\section{EXCLUDABLE BENEFITS AND PROFITABILITY FUNCTIONS}

Before deriving and discussing the conditions under which linking the negotiations on the two economic issues is an equilibrium of the game presented in Section 2, it is important to introduce some additional elements which characterise the structure of the game. As shown below, the equilibrium condition depends, among other things, on two features of the game:

- the degree of excludability of the benefits arising from the agreement (the ' $t$-agreement') which is linked to the environmental agreement (the ' $a$-agreement'); 
- the shape of the profitability functions describing the gains achieved by cooperators in the two separate agreements and in the linked agreement.

Let us therefore characterise both the degree of excludability of cooperation benefits and the shape of the profitability functions. Let us use the example of $R \& D$ cooperation. In this case, the idea of issue linkage is to link environmental cooperation, which provides non-excludable benefits, with R\&D cooperation, which provides excludable, or at least partly excludable, benefits. In this way, the incentive to free-ride on environmental benefits can be offset by the incentive to appropriate the excludable benefits yielded by $R \& D$ cooperation.

It is well known that the degree of excludability of R\&D and technological innovation may not be perfect. Therefore, in this chapter we consider two basic cases. In the first, the benefits from cooperation on the 't-agreement' are sufficiently excludable to provide incentives for the formation of a grand coalition on this agreement. In the second, a coalition smaller than the grand coalition forms on the ' $t$-agreement', because benefits from cooperation spill over to the free-riders.

Let $\gamma, \gamma \in[0,1]$, be the degree of excludability of the benefits produced by ' $t$-agreement'. If $\gamma=1$, then benefits are perfectly excludable and they go only to cooperators. Hence, $Q_{t}\left(c_{t}\right)=0, \forall c_{t} \in[2, n]$. If $\gamma=0$, the benefits produced by cooperators are a public good and go to free-riders as well. In the case of R\&D cooperation, $\gamma$ depends on the possibility of patenting innovations and on the duration and extension of the patent. If $0<\gamma<1$, then we have a case of partial excludability. The smaller $\gamma$, the larger the benefits achieved by free-riders and hence the larger the function $Q_{t}\left(c_{t}\right)$ for any given $c_{t}$.

Let $\gamma^{\circ}$ denote the value of $\gamma$ such that $P_{t}\left(c_{t}^{*}\right)=Q_{t}\left(c_{t}^{*}-1\right)$ when $c_{t}^{*}=n$. In words, when $\gamma \geq \gamma^{\circ}$, the degree of excludability is so high that the benefits from participating in the agreement are larger than the benefits from freeriding for all $2 \leq c_{t} \leq n$. As a consequence, in this case, if the profitability condition is satisfied for all $c_{t}$ in the interval $[2, n]$, then the grand coalition forms, that is, all players prefer to sign the ' $t$-agreement' $\left(c_{t}^{*}=n\right) .{ }^{4} \mathrm{By}$ contrast, when $\gamma<\gamma^{\circ}$, only a partial coalition forms on the ' $t$-issue', that is, only a subset of countries sign the ' $t$-agreement'. The function $Q_{t}\left(c_{t}\right)$ for low $\gamma$, $\gamma=\gamma^{\circ}$ and high $\gamma$ is represented in Figure 3.2.

In the rest of the chapter we will analyse two cases:

Case A: $\gamma^{\circ} \leq \gamma \leq 1$, that is, the case in which all players would like to sign the ' $t$-agreement' $\left(c_{t}^{*}=n\right)$;

Case B: $0<\gamma<\gamma^{\circ}$, that is, in the case of the ' $t$-agreement' a partial coalition forms $\left(2 \leq c_{t}^{*}<n\right)$. 


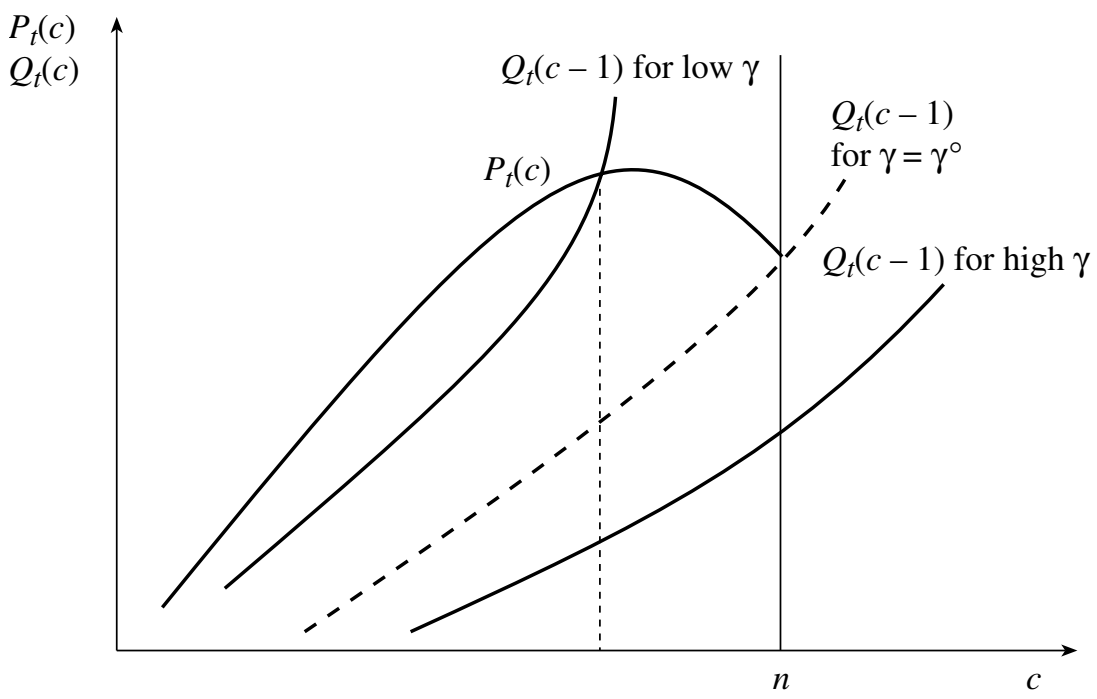

Figure 3.2 Payoff functions for different values of $\gamma$

As for the shape of the profitability functions, the following assumption will be used:

A.10 (Incomplete monotonicity): The payoff functions $P_{a}\left(c_{a}\right), Q_{a}\left(c_{a}\right)$, and $Q_{t}\left(c_{t}\right)$ are assumed to be monotonically increasing in $c_{a}$ and $c_{t}$ respectively. The payoff function $P_{t}\left(c_{t}\right)$ is assumed to be increasing in $c_{t}$ for $c_{t}<c_{t}{ }^{\circ}$ and monotonically decreasing in $c_{t}$ for $c_{t}>c_{t}{ }^{\circ}$.

The monotonicity of $P_{a}\left(c_{a}\right), Q_{a}\left(c_{a}\right)$, and $Q_{t}\left(c_{t}\right)$ is a standard assumption in the economic literature on environmental coalition formation (see the surveys by Barrett, 1997; Carraro, 1998; Carraro and Marchiori, 2002). In particular, a monotonic $P_{a}\left(c_{a}\right)$ implies that the benefits from providing a public good (for example, from abating emissions) increase with the number of countries that participate in the agreement.

As for the payoff function $P_{t}\left(c_{t}\right)$, we assume that it initially increases with the size of the coalition $c$ and then it decreases (it is hump-shaped). As shown in Carraro and Siniscalco (1997), this is actually the case when the ' $t$-agreement' concerns $\mathrm{R} \& \mathrm{D}$ cooperation and this is generally the case when benefits from cooperation are (partly) excludable. In the case of R\&D cooperation, the intuition is as follows. The decision to sign the R\&D agreement has two positive effects for signatories: on the one hand, production costs decrease because cooperative R\&D makes more efficient technologies 
available; on the other hand, market share increases because firms with lower costs have a higher market share (a standard Cournot oligopoly is assumed). However, this latter effect becomes smaller and smaller as the coalition size increases and goes to zero when $c_{t}=n$. Hence, the benefit from belonging to the coalition $c_{t}$ decreases with the size of $c_{t}$ when $c_{t}$ is above a given intermediate value $c_{t}^{\circ}$.

Notice that, in Case A, if $P_{t}\left(c_{t}^{*}\right)$ is hump-shaped, then $P_{t}\left(c_{t}^{*}=n\right) \geq$ $P_{t}\left(c_{t}^{*}+1\right)$. Moreover, at the equilibrium $P_{t}\left(c_{t}^{*}=n\right) \geq Q_{t}\left(c_{t}^{*}-1\right)$. We also assume for simplicity that, in case A, $P_{t}\left(c_{t}^{*}+1\right) \geq Q_{t}\left(c_{t}^{*}=n\right)$. Hence, $Q_{t}\left(c_{t}^{*}\right)$ $\leq P_{t}\left(c_{t}^{*}\right)$.

The shape of the payoff functions for cooperators and free-riders is shown in Figure 3.3 for Case A $\left(\gamma^{\circ}<\gamma \leq 1\right)$ and in Figure 3.4 for Case B $\left(0<\gamma \leq \gamma^{\circ}\right)$.

Notice that in Figures 3.3 and 3.4 we represent the case in which $c_{a}^{*}<c_{t}^{*}$. This reflects the implicit assumption that the equilibrium coalition in the
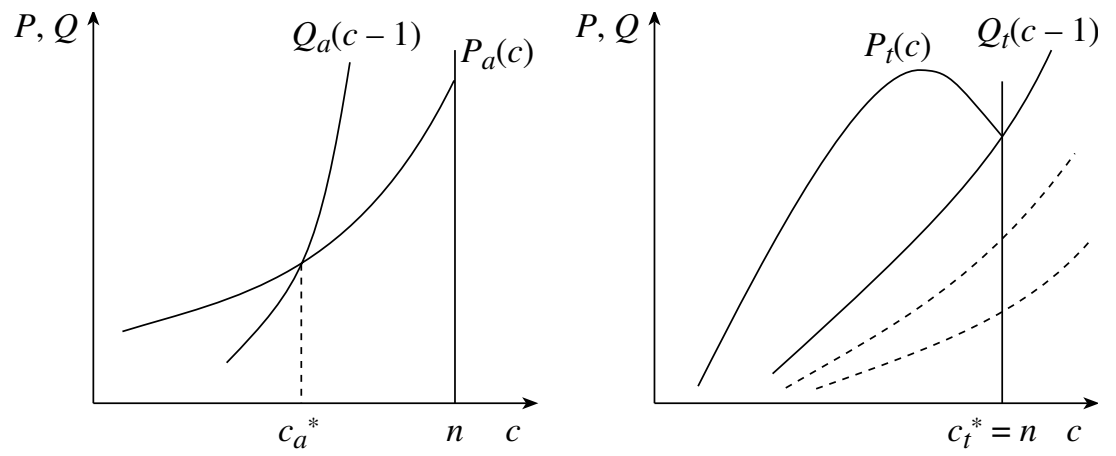

Figure 3.3 Shape of the payoff functions in Case $A\left(\gamma^{\circ}<\gamma \leq 1\right)$
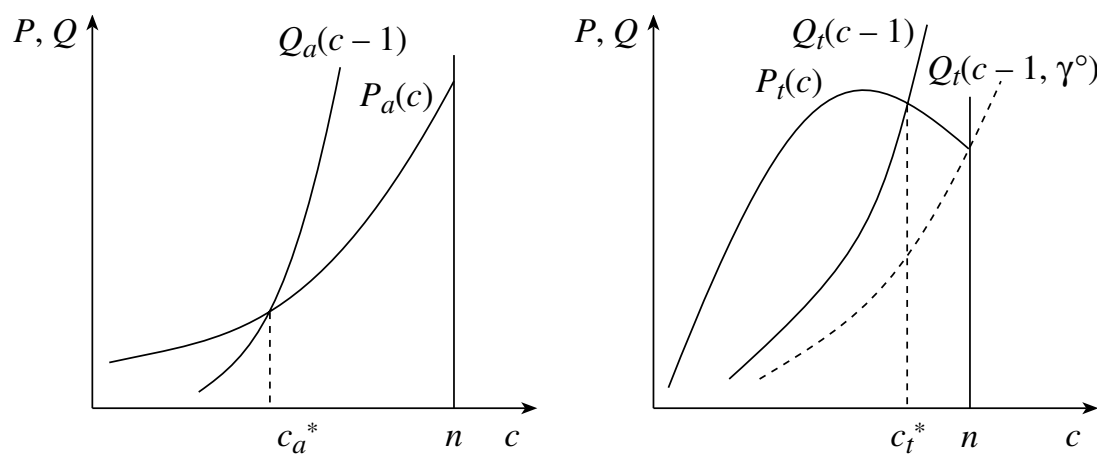

Figure 3.4 Shape of the payoff functions in Case $B\left(0<\gamma \leq \gamma^{\circ}\right)$ 
case of an agreement on a public good is smaller than the equilibrium coalition in the case of an agreement on a (quasi) club good. Indeed, where $c_{a}^{*}$ $\geq c_{t}^{*}$, the idea of linking the negotiation on the provision of a public good to a different negotiation would be meaningless.

Also notice that the monotonicity of $Q_{a}(c)$ and $Q_{t}(c)$ implies the monotonicity of $Q_{u}(c)$. By contrast, $P_{u}(c)=P_{a}(c)+P_{t}(c)$ can be both monotonic or hump-shaped. However, given Assumption A.10, if $P_{u}(c)$ is humpshaped, it is monotonically increasing for $c_{u}<c_{u}^{\circ}$ and monotonically decreasing for $c_{u}>c_{u}^{\circ}$, with $c_{u}^{\circ}>c_{t}^{\circ}$.

In order to concentrate on the free-riding problem, let us assume that (i) issue linkage actually increases the number of players who provide the public good, that is:

$$
c_{u}^{*}>c_{a}^{*}
$$

and (ii) issue linkage is profitable:

$$
P_{u}\left(c_{u}^{*}\right) \geq P_{u}(0)
$$

Therefore, let us focus on the stability of the linked agreement. First, we show that $c_{u}^{*}$ is smaller than $c_{t}^{*}$, namely that the equilibrium coalition emerging from the linked negotiation is always smaller than the equilibrium coalition in the ' $t$-agreement'. 5

Proposition 1: At the equilibrium, $c_{u}^{*} \leq c_{t}^{*}$, that is, the number of players who participate in the linked agreement is always smaller than or equal to the number of players who participate in the (club good) agreement linked to the public good agreement.

Proof: The linked agreement is internally stable if $P_{u}\left(c_{u}^{*}\right) \geq Q_{u}\left(c_{u}^{*}-1\right)$, that is, if:

$$
Q_{a}\left(c_{u}^{*}-1\right)-P_{a}\left(c_{u}^{*}\right) \leq P_{t}\left(c_{u}^{*}\right)-Q_{t}\left(c_{u}^{*}-1\right)
$$

When $c_{u}^{*}>c_{a}^{*}$, the left-hand side of (3.7) is positive because there is an incentive to free-ride on the ' $a$-agreement' for all $c>c_{a}^{*}$. This implies that the right-hand side is also positive, that is, $P_{t}\left(c_{u}^{*}\right)>Q_{t}\left(c_{u}^{*}-1\right)$. Therefore, as far as the ' $t$-agreement' is concerned, there is still an incentive to enter the coalition. Hence, $c_{u}^{*}$ must be smaller than or equal to the equilibrium coalition size $c_{t}^{*}$, that is, $c_{u}^{*} \leq c_{t}^{*}$.

The conclusion shown by Proposition 1 holds both in Case A and in Case B. The only difference is that, in Case A, $P_{t}(c)-Q_{t}(c-1)$ is non-negative for 

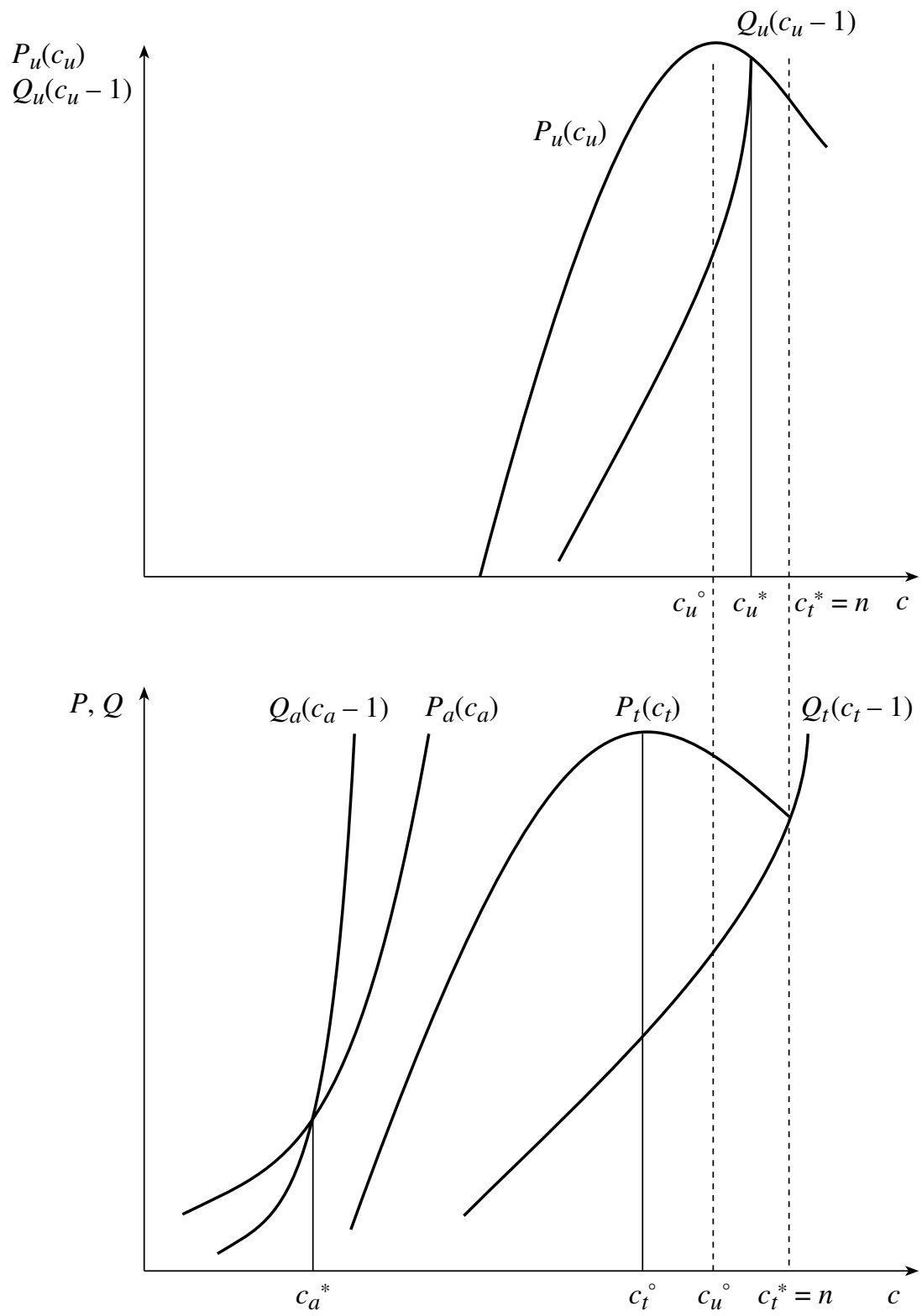

Figure 3.5 Payoff functions for the linked and separate agreements in Case $A$ and $c_{u}^{*}>c_{u}^{\circ}$ 


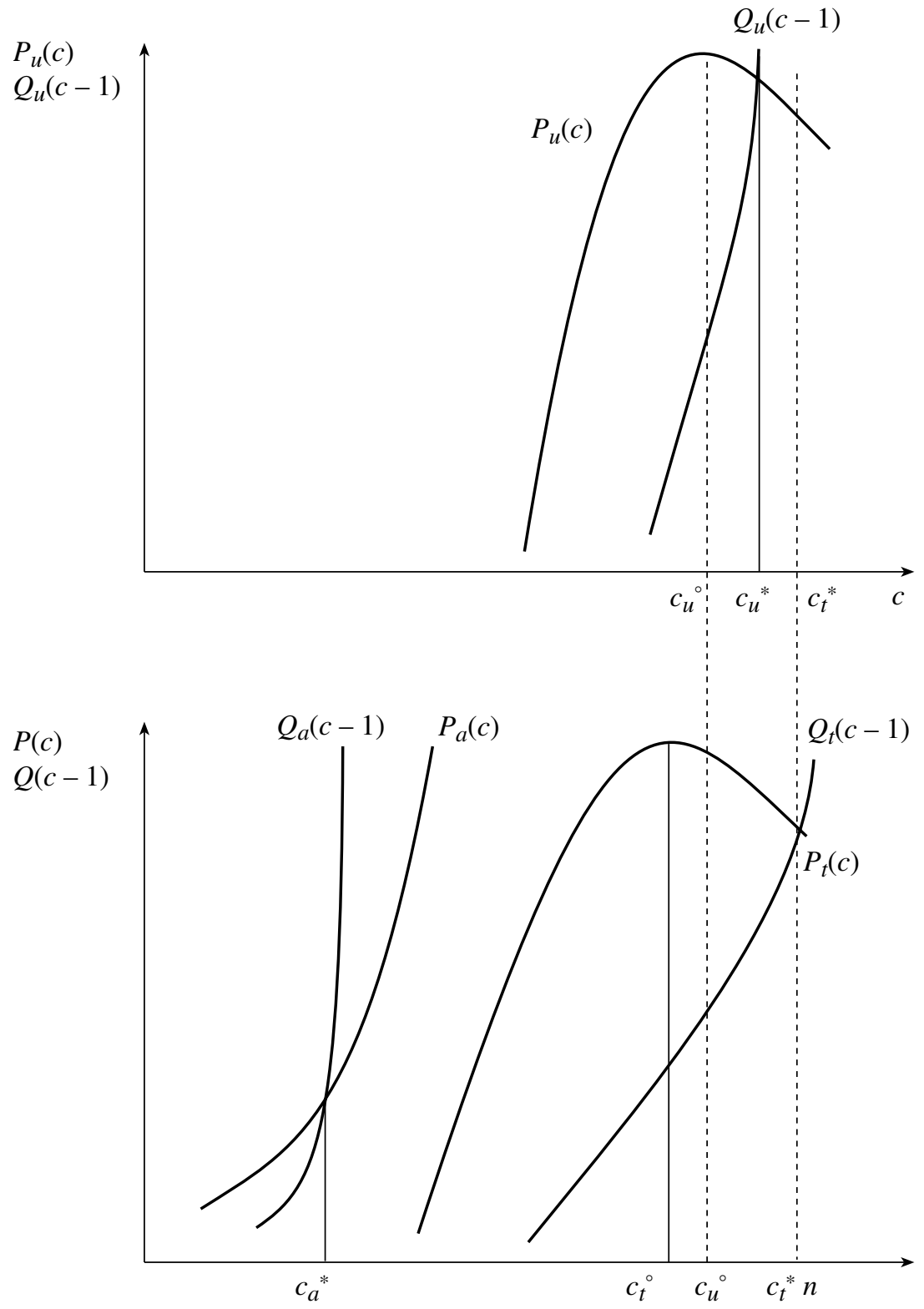

Figure 3.6 Payoff functions for the linked and separate agreements in Case B 
all $c$ in the interval $[2, n]$ because this is the condition which implies $c_{t}^{*}=n$. Hence, $P_{t}(c)-Q_{t}(c-1)$ is obviously non-negative also for $c=c_{u}^{*}$. Note that Proposition 1 and the preceding analysis lead to the following ordering:

$$
c_{a}^{*}<c_{u}^{*} \leq c_{t}^{*} \text { and } c_{t}^{\circ} \leq c_{u}^{\circ} .
$$

The payoff functions of the two separate games and of the linked game are shown in Figures 3.5 and 3.6 for Cases A and B respectively. Both figures deal with the situation in which $c_{u}^{*}>c_{u}^{\circ}$. These figures will be useful to clarify the analysis of the equilibrium of the game.

\section{THE EQUILIBRIUM OF THE GAME}

\subsection{Case A: Linkage with a Perfect Club Good}

We are now ready to determine players' equilibrium choice in the first stage of the game. In Case A, the situation is simpler, because, if players negotiate only on the ' $t$-agreement', at the equilibrium all countries would like to sign it $\left(c_{t}^{*}=n\right)$. Hence, if players disagree on linkage, either they cooperate on both the ' $a$-agreement' and the ' $t$-agreement', or they free-ride only on the first one. Their payoff is therefore $P_{a}\left(c_{a}^{*}\right)+P_{t}\left(c_{t}^{*}\right)$ or $Q_{a}\left(c_{a}^{*}\right)+P_{t}\left(c_{t}^{*}\right)$, where $P_{a}\left(c_{a}^{*}\right)+P_{t}\left(c_{t}^{*}\right) \leq Q_{a}\left(c_{a}^{*}\right)+P_{t}\left(c_{t}^{*}\right)$ because the monotonicity of $P_{a}\left(c_{a}\right)$ and conditions (3.2a) and (3.2b) imply $P_{a}\left(c_{a}^{*}\right) \leq Q_{a}\left(c_{a}^{*}\right)$. As a consequence:

Proposition 2: Assume A.1 to A.10 hold and $\gamma^{\circ}<\gamma \leq 1$, that is, $c_{t}^{*}=n$. If $(i)$ $P_{u}\left(c_{u}\right)$ is monotonic in the interval [2,n]; or (ii) $c_{u}^{*}<c_{u}^{\circ}$; or (iii) $c_{u}^{*}<c_{u}^{\circ}$, $c_{u}^{\circ}<n$, and $P_{t}\left(c_{u}^{*}\right)-Q_{t}\left(c_{u}^{*}\right)$ is smaller than $Q_{a}\left(c_{u}^{*}\right)-P_{a}\left(c_{u}^{*}\right)>0$, then players adopt issue linkage under unanimity voting if:

$$
\left[P_{a}\left(c_{u}^{*}\right)-Q_{a}\left(c_{a}^{*}\right)\right]>\left[P_{t}\left(c_{t}^{*}=n\right)-P_{t}\left(c_{u}^{*}\right)\right]
$$

If instead (iv) $c_{u}^{*}>c_{u}^{\circ}, c_{u}^{\circ}<n$ and $P_{t}\left(c_{u}^{*}\right)-Q_{t}\left(c_{u}^{*}\right)$ is positive and larger than $Q_{a}\left(c_{u}^{*}\right)-P_{a}\left(c_{u}^{*}\right) ;$ or $(v) c_{u}^{*}=n>c_{u}^{\circ}$, the condition for players to adopt issue linkage becomes:

$$
\left[Q_{a}\left(c_{u}^{*}\right)-Q_{a}\left(c_{a}^{*}\right)\right]>\left[P_{t}\left(c_{t}^{*}=n\right)-Q_{t}\left(c_{u}^{*}\right)\right]
$$

Proof: If $P_{u}\left(c_{u}\right)$ is monotonic or $P_{u}\left(c_{u}\right)$ is hump-shaped with $c_{u}^{*}<c_{u}^{\circ}$, then at the equilibrium $P_{u}\left(c_{u}^{*}+1\right) \geq P_{u}\left(c_{u}^{*}\right)$, which implies $P_{u}\left(c_{u}^{*}\right)=P_{a}\left(c_{u}^{*}\right)+P_{t}\left(c_{u}^{*}\right)<$ $Q_{u}\left(c_{u}^{*}\right)=Q_{a}\left(c_{u}^{*}\right)+Q_{t}\left(c_{u}^{*}\right)$ because of (3.2a) and (3.2b). Hence, all players vote for issue linkage if $P_{u}\left(c_{u}^{*}\right)=P_{a}\left(c_{u}^{*}\right)+P_{t}\left(c_{u}^{*}\right)$ - the worst payoff they can get 
under issue linkage - is larger than $Q_{a}\left(c_{a}^{*}\right)+P_{t}\left(c_{t}^{*}\right)$ - the largest payoff they get without linkage. Hence, (3.9) must hold. If $P_{u}\left(c_{u}\right)$ is hump-shaped with $c_{u}^{*} \geq c_{u}^{\circ}, c_{u}^{\circ}<n$, then $Q_{u}\left(c_{u}^{*}\right)$ may be smaller than $P_{u}\left(c_{u}^{*}\right)$. If not, (3.9) holds again. $Q_{u}\left(c_{u}^{*}\right)$ is smaller than $P_{u}\left(c_{u}^{*}\right)$ if $P_{t}\left(c_{u}^{*}\right)-Q_{t}\left(c_{u}^{*}\right)>Q_{a}\left(c_{u}^{*}\right)-P_{a}\left(c_{u}^{*}\right)$. Notice that $Q_{a}\left(c_{u}\right)-P_{a}\left(c_{u}\right)>0$ at $c=c_{u}^{*}$, because $c_{a}^{*}<c_{u}^{*}$. Hence, a necessary condition for $Q_{u}\left(c_{u}^{*}\right)<P_{u}\left(c_{u}^{*}\right)$ is $P_{t}\left(c_{u}^{*}\right)-Q_{t}\left(c_{u}^{*}\right)>0$, which holds because $c_{u}^{*}$ $<c_{t}^{*}$. As a consequence, if $P_{t}\left(c_{u}^{*}\right)-Q_{t}\left(c_{u}^{*}\right)>Q_{a}\left(c_{u}^{*}\right)-P_{a}\left(c_{u}^{*}\right)>0$, all players vote in favour of issue linkage when $Q_{u}\left(c_{u}^{*}\right)=Q_{a}\left(c_{u}^{*}\right)+Q_{t}\left(c_{u}^{*}\right)$ - the worst payoff they can get under issue linkage - is larger than $Q_{a}\left(c_{a}^{*}\right)+P_{t}\left(c_{t}^{*}\right)-$ the largest payoff they get without linkage. Hence, (3.10) must hold. Finally, when $c_{u}^{*}=n$, there is no incentive to defect for any $c_{u} \leq n$. Hence, $P_{u}\left(c_{u}^{*}\right)>$ $P_{t}\left(c_{u}^{*}+1\right)>Q_{u}\left(c_{u}^{*}\right)$. As a consequence, $Q_{u}\left(c_{u}^{*}\right)=Q_{a}\left(c_{u}^{*}\right)+Q_{t}\left(c_{u}^{*}\right)$ must be larger than $Q_{a}\left(c_{a}^{*}\right)+P_{t}\left(c_{t}^{*}\right)$, that is, (3.10) must hold (Q.E.D.).

How can conditions (3.9) and (3.10) be interpreted? $\left[P_{a}\left(c_{u}^{*}\right)-Q_{a}\left(c_{a}^{*}\right)\right]-$ the left-hand side of (3.9) - represents the gain or loss that a free-rider on the ' $a$-agreement' achieves from joining the expanded coalition. It can also be written as $\left[P_{a}\left(c_{u}^{*}\right)-P_{a}\left(c_{a}^{*}\right)\right]-\left[Q_{a}\left(c_{a}^{*}\right)-P_{a}\left(c_{a}^{*}\right)\right]$, where the first term is the increased gain that a cooperator on the ' $a$-agreement' achieves from expanding the coalition, whereas the second term is a free-rider's relative gain when a coalition $c_{a}^{*}$ forms. $\left[P_{t}\left(c_{t}^{*}\right)-P_{t}\left(c_{u}^{*}\right)\right]$ is the possible gain or loss that goes to a cooperator in the ' $t$-agreement' when the coalition size moves from $c_{t}^{*}$ to $c_{u}^{*}$. Hence, (3.9) says that the gain (loss) that a free-rider on the 'a-agreement' achieves from joining the expanded coalition must be larger (smaller) than the gain (loss) that goes to a cooperator in the 't-agreement' when the coalition size moves from $c_{t}^{*}$ to $c_{u}^{*}$.

Condition (10) has a different interpretation. $\left[Q_{a}\left(c_{u}^{*}\right)-Q_{a}\left(c_{a}^{*}\right)\right]$ is the gain that goes to a free-rider when more players cooperate on the provision of a public good. $\left[P_{t}\left(c_{t}^{*}\right)-Q_{t}\left(c_{u}^{*}\right)\right]=\left[P_{t}\left(c_{t}^{*}\right)-P_{t}\left(c_{u}^{*}\right)\right]+\left[P_{t}\left(c_{u}^{*}\right)-Q_{t}\left(c_{u}^{*}\right)\right]$ is the possible gain or loss that goes to a cooperator in the 't $t$-agreement' when the coalition size moves from $c_{t}^{*}$ to $c_{u}^{*}$, plus the excess benefits of cooperation when $c_{u}^{*}<c_{t}^{*}$ (recall that $P_{t}(c)>Q_{t}(c)$ for all $c<c_{t}^{*}=n$, because the agreement concerns a perfect club good). Hence, issue linkage is chosen by all players if the gain that goes to a free-rider when more players cooperate in the provision of a public good is larger than the excess benefits of cooperation when $c_{u}^{*}<c_{t}^{*}$ plus the gain (loss) that goes to a cooperator in the 't-agreement' when the coalition size moves from $c_{t}^{*}$ to $c_{u}^{*}$.

\subsection{Case B: Linkage with an Imperfect Club Good}

Let us now consider the second case, in which the club good issue linked to the public good issue is an imperfect club good. This implies that the 
benefits from cooperation on the ' $t$-agreement' which spill over to freeriders are strong enough to induce some players not to join the coalition. Hence, when players negotiate on the ' $t$-agreement' only, the equilibrium coalition $c_{t}^{*}$ is not the grand coalition, that is, $c_{t}^{*}<n$.

In this context, it is still important to adopt issue linkage as a strategy to increase the coalition size on the ' $a$-agreement' because $c_{a}^{*}<c_{t}^{*}$. Hence, issue linkage helps players to achieve a coalition $c_{u}^{*}$ larger than $c_{a}^{*}$, but smaller than $c_{t}^{*}$ (Proposition 1). However, the benefits of a larger coalition on the ' $a$-agreement' must be traded off with the loss of a smaller coalition in the ' $t$-agreement'.

The first step to determine the equilibrium of the game is the analysis of the payoffs of the four types of players that emerge in the second stage of the game. We need to compare:

- $P_{a}\left(c_{a}^{*}\right)+P_{t}\left(c_{t}^{*}\right)$, the payoff of a cooperator in both separate agreements;

- $P_{a}\left(c_{a}^{*}\right)+Q_{t}\left(c_{t}^{*}\right)$, the payoff of a player who cooperates in the ' $a$ agreement' but free-rides on the other one;

- $Q_{a}\left(c_{a}^{*}\right)+P_{t}\left(c_{t}^{*}\right)$, the payoff of a player who cooperates in the ' $t$ agreement' but free-rides on the other one;

- $Q_{a}\left(c_{a}^{*}\right)+Q_{t}\left(c_{t}^{*}\right)$, the payoff of a free-rider on both separate agreements.

First, notice that $P_{a}\left(c_{a}^{*}\right)+P_{t}\left(c_{t}^{*}\right)<Q_{a}\left(c_{a}^{*}\right)+P_{t}\left(c_{t}^{*}\right)$ and $P_{a}\left(c_{a}^{*}\right)+Q_{t}\left(c_{t}^{*}\right)<$ $Q_{a}\left(c_{a}^{*}\right)+Q_{t}\left(c_{t}^{*}\right)$ because the monotonicity of $P_{a}(c)$ implies $P_{a}\left(c_{a}^{*}\right)<Q_{a}\left(c_{a}^{*}\right)$. Hence, the largest payoff in the case of two separate agreements is the one in which a player free-rides on both agreements iff:

$$
P_{t}\left(c_{t}^{*}\right)<Q_{t}\left(c_{t}^{*}\right)
$$

In the rest of this chapter we will use (3.11), which says that a free-rider on the ' $t$-agreement' achieves a larger payoff than a cooperator in the same agreement. This is reasonable if the degree of appropriability of the benefits from cooperation in the ' $t$-agreement' is sufficiently low. We assume that this is the case for $\gamma<\gamma^{\circ}$.

Then, the conditions for issue linkage to be an equilibrium strategy are described by the following Proposition:

Proposition 3: Assume A.1 to A.10 hold, $0 \leq \gamma<\gamma^{\circ}$, that is, $c_{t}^{*}<n$, and $P_{t}\left(c_{t}^{*}\right)<Q_{t}\left(c_{t}^{*}\right)$. If (i) $P_{u}\left(c_{u}\right)$ is monotonic in the interval [2, n]; or (ii) $c_{u}^{*}<$ $c_{u}^{\circ}$; or (iii) $c_{u}^{*} \geq c_{u}^{\circ}, c_{u}^{\circ}<n$, and $P_{t}\left(c_{u}^{*}\right)-Q_{t}\left(c_{u}^{*}\right)$ is smaller than $Q_{a}\left(c_{u}^{*}\right)-$ $P_{a}\left(c_{u}^{*}\right)>0$, then players adopt issue linkage under unanimity voting iff condition (3.12) holds, that is: 


$$
\left[P_{a}\left(c_{u}^{*}\right)-Q_{a}\left(c_{a}^{*}\right)\right]>\left[Q_{t}\left(c_{t}^{*}\right)-P_{t}\left(c_{u}^{*}\right)\right]
$$

If $c_{u}^{*}>c_{u}^{\circ}, c_{u}^{\circ}<n$, and $P_{t}\left(c_{u}^{*}\right)-Q_{t}\left(c_{u}^{*}\right)$ is positive and larger than $Q_{a}\left(c_{u}^{*}\right)-$ $P_{a}\left(c_{u}^{*}\right)$, the condition for issue linkage to be adopted becomes:

$$
\left[Q_{a}\left(c_{u}^{*}\right)-Q_{a}\left(c_{a}^{*}\right)\right]>\left[Q_{t}\left(c_{t}^{*}\right)-Q_{t}\left(c_{u}^{*}\right)\right]
$$

Proof: If $P_{u}\left(c_{u}\right)$ is monotonic or $P_{u}\left(c_{u}\right)$ is hump-shaped with $c_{u}^{*}<c_{u}^{\circ}$, then at the equilibrium $P_{u}\left(c_{u}^{*}+1\right) \geq P_{u}\left(c_{u}^{*}\right)$, which implies $P_{u}\left(c_{u}^{*}\right)=P_{a}\left(c_{u}^{*}\right)+P_{t}\left(c_{u}^{*}\right)$ $<Q_{u}\left(c_{u}^{*}\right)=Q_{a}\left(c_{u}^{*}\right)+Q_{t}\left(c_{u}^{*}\right)$ because of (3.2a and 3.2b). Hence, all players vote for issue linkage if $P_{u}\left(c_{u}^{*}\right)=P_{a}\left(c_{u}^{*}\right)+P_{t}\left(c_{u}^{*}\right)$ - the worst payoff they can get under issue linkage - is larger than $Q_{a}\left(c_{a}^{*}\right)+Q_{t}\left(c_{t}^{*}\right)$ - the largest payoff they get without linkage. Hence, (3.12) must hold.

If $P_{u}\left(c_{u}\right)$ is hump-shaped with $c_{u}^{*} \geq c_{u}^{\circ}, c_{u}^{\circ}<n$, then $Q_{u}\left(c_{u}^{*}\right)$ may be smaller than $P_{u}\left(c_{u}^{*}\right)$. If not, (3.12) holds again. $Q_{u}\left(c_{u}^{*}\right)$ is smaller than $P_{u}\left(c_{u}^{*}\right)$ if $P_{t}\left(c_{u}^{*}\right)$ $-Q_{t}\left(c_{u}^{*}\right)>Q_{a}\left(c_{u}^{*}\right)-P_{a}\left(c_{u}^{*}\right)$. Notice that $Q_{a}\left(c_{u}\right)-P_{a}\left(c_{u}\right)>0$ at $c=c_{u}^{*}$, because $c_{a}^{*}<c_{u}^{*}$. Hence, a necessary condition for $Q_{u}\left(c_{u}^{*}\right)<P_{u}\left(c_{u}^{*}\right)$ is $P_{t}\left(c_{u}^{*}\right)-Q_{t}\left(c_{u}^{*}\right)>$ 0 , which holds for $c_{u}^{*}<c_{t}^{*}$. As a consequence, if $P_{t}\left(c_{u}^{*}\right)-Q_{t}\left(c_{u}^{*}\right)>Q_{a}\left(c_{u}^{*}\right)-$ $P_{a}\left(c_{u}^{*}\right)>0$, all players vote in favour of issue linkage when $Q_{u}\left(c_{u}^{*}\right)=Q_{a}\left(c_{u}^{*}\right)+$ $Q_{t}\left(c_{u}^{*}\right)$ - the worst payoff they can get under issue linkage - is larger than $Q_{a}\left(c_{a}^{*}\right)+Q_{t}\left(c_{t}^{*}\right)-$ the largest payoff they get without linkage. Hence, (3.13) must hold (Q.E.D.).

The interpretation of this Proposition goes as follows. Again we have two conditions for issue linkage to be chosen by all players in the first stage of the game. Consider the first one. The right hand side of (3.12) $-\left[Q_{t}\left(c_{t}^{*}\right)-\right.$ $\left.P_{t}\left(c_{u}^{*}\right)\right]$ - is the loss from reducing the coalition on the ' $t$-agreement' from $c_{t}^{*}$ to $c_{u}^{*}$ (Proposition 1 has shown that $c_{t}^{*} \geq c_{u}^{*}$ ). This loss can be written as $Q_{t}\left(c_{t}^{*}\right)-P_{t}\left(c_{u}^{*}\right)=\left[Q_{t}\left(c_{t}^{*}\right)-Q_{t}\left(c_{u}^{*}\right)\right]-\left[P_{t}\left(c_{u}^{*}\right)-Q_{t}\left(c_{u}^{*}\right)\right]$ where the first term represents a free-rider's loss when they get fewer benefits from a smaller coalition, whereas the second term represents the excess benefit of cooperation when $c_{u}^{*}<c_{t}^{*}$.

The left-hand side of (3.12) is the same as the left-hand side of (3.9). Hence, it represents the gain or loss which a free-rider on the ' $a$-agreement' achieves when joining the expanded coalition. It can also be written as $\left[P_{a}\left(c_{u}^{*}\right)-P_{a}\left(c_{a}^{*}\right)\right]-\left[Q_{a}\left(c_{a}^{*}\right)-P_{a}\left(c_{a}^{*}\right)\right]$. The positivity of $Q_{t}\left(c_{t}^{*}\right)-P_{t}\left(c_{u}^{*}\right)$ implies that (3.12) holds if $P_{a}\left(c_{u}^{*}\right)-Q_{a}\left(c_{a}^{*}\right)$ is also positive, that is, if the increased gain which a cooperator on the 'a-agreement' achieves from expanding the coalition is larger than a free-rider's relative gain when a coalition $c_{a}^{*}$ forms. 
This is only a necessary condition. The sufficient condition says that the increased gain which a cooperator on the 'a-agreement' (for example, a signatory of an environmental agreement) achieves from expanding the coalition from $c_{a}^{*}$ to $c_{u}^{*}$, plus the excess benefit of cooperation on the 't-agreement' when $c_{u}^{*}<c_{t}^{*}$, must be larger than a free-rider's relative gain when a coalition $c_{a}^{*}$ forms plus the loss that a free-rider suffers because of the smaller spillovers from the reduced cooperation on the 't-agreement'.

The second condition - the inequality (3.13) - is new and says that the benefits enjoyed by a free-rider on the 'a-agreement' when the coalition size increases must be larger than the loss suffered by a free-rider on the 'tagreement' when the number of signatories of the 't-agreement' decrease from $c_{t}^{*}$ to $c_{u}^{*}$ (recall that benefits from cooperation spill over to free-riders in the case of the ' $t$-agreement' also).

\section{SUMMARY AND CONCLUSIONS}

The previous section has identified four conditions under which all players of the game prefer to negotiate on two linked issues rather than on the two issues separately. In order to simplify the message which can be derived from Propositions 2 and 3, let us assume that free-riders on the linked agreement are better off than cooperators $\left[P_{u}\left(c_{u}^{*}\right)<Q_{u}\left(c_{u}^{*}\right)\right]$. This is the most frequent case in coalition theory. Then, issue linkage is the equilibrium strategy under unanimity voting if:

$$
\left[P_{a}\left(c_{u}^{*}\right)-Q_{a}\left(c_{a}^{*}\right)\right]>\left[Q_{t}\left(c_{t}^{*}\right)-P_{t}\left(c_{u}^{*}\right)\right]
$$

in the case of an imperfect club good $\left(c_{t}^{*}<n\right)$, or

$$
\left[P_{a}\left(c_{u}^{*}\right)-Q_{a}\left(c_{a}^{*}\right)\right]>\left[P_{t}\left(c_{t}^{*}=n\right)-P_{t}\left(c_{u}^{*}\right)\right]
$$

in the case of a perfect club good $\left(c_{t}^{*}=n\right)$.

What policy message can be derived from these inequalities? First, let us underline a necessary condition for issue linkage to be adopted in the first stage of the game. A free-rider on the public good agreement who enters the coalition on the linked agreement must get a higher payoff $\left[\mathrm{P}_{\mathrm{a}}\left(\mathrm{c}_{\mathrm{u}}^{*}\right)>\right.$ $\left.\mathrm{Q}_{\mathrm{a}}\left(\mathrm{c}_{\mathrm{a}}^{*}\right)\right]$. This is a prerequisite without which issue linkage is not chosen. Hence, public good (for example, environmental) benefits provided by a larger coalition must be perceived as sufficiently large.

Then, there is the necessary and sufficient condition. A free-rider on the public good agreement who enters the coalition on the linked agreement must not only increase his payoff, but this positive change must be larger 
than the loss a player may suffer because the club good coalition becomes smaller, (this is particularly clear in condition (3.9) but it is also true in (3.12).

This highlights the trade-off that players face when deciding whether or not to adopt issue linkage. Consider again the example of an environmental negotiation linked to a negotiation on $\mathrm{R} \& \mathrm{D}$ cooperation. On the one hand, players would like to reap the benefits provided by a larger environmental coalition. On the other hand, they know that though issue linkage increases the number of environmental cooperators, it also decreases the participants in the R\&D cooperation agreement. Hence, environmental benefits could be offset by technological losses.

A similar argument holds when free-riders on the linked agreement are worse off than cooperators $\left[\mathrm{P}_{\mathrm{u}}\left(\mathrm{c}_{\mathrm{u}}^{*}\right)>\mathrm{Q}_{\mathrm{u}}\left(\mathrm{c}_{\mathrm{u}}^{*}\right)\right]$. In this case the conditions for issue linkage to be adopted under unanimity voting are:

$$
\left[Q_{a}\left(c_{u}^{*}\right)-Q_{a}\left(c_{a}^{*}\right)\right]>\left[Q_{t}\left(c_{t}^{*}\right)-Q_{t}\left(c_{u}^{*}\right)\right]
$$

in the case of an imperfect club good $\left(c_{t}^{*}<n\right)$, or

$$
\left[Q_{a}\left(c_{u}^{*}\right)-Q_{a}\left(c_{a}^{*}\right)\right]>\left[P_{t}\left(c_{t}^{*}=n\right)-Q_{t}\left(c_{u}^{*}\right)\right]
$$

in the case of a perfect club good $\left(c_{t}^{*}=n\right)$.

There is no necessary condition to be stressed, because the monotonicity of $Q_{a}\left(c_{a}\right)$ implies $Q_{a}\left(c_{u}^{*}\right)>Q_{a}\left(c_{a}^{*}\right)$. The necessary and sufficient condition says that the gain $\left[\mathrm{Q}_{\mathrm{a}}\left(\mathrm{c}_{\mathrm{u}}^{*}\right)-\mathrm{Q}_{\mathrm{a}}\left(\mathrm{c}_{\mathrm{a}}^{*}\right)\right]$ that a free-rider achieves when freeriding on a larger public good agreement must be larger than the loss a player may suffer because the club good coalition becomes smaller.

As a consequence, when proposing or advocating issue linkage, policymakers must be careful in assessing two crucial elements. The first crucial element is the relative change of the coalition sizes $c_{u}^{*}-c_{a}^{*}$ and $c_{t}^{*}-c_{u}^{*}$. The greater $c_{u}^{*}-c_{a}^{*}$ and the smaller $c_{t}^{*}-c_{u}^{*}$, the larger the likelihood that conditions (3.12) (or (3.9)) and (3.13) (or (3.10)) be satisfied. The second crucial element is the relative change in the players' payoffs. The greater the increased benefits induced by greater cooperation on the public good issue, the greater the likelihood that issue linkage be adopted. Similarly, the smaller the loss from a reduced cooperation on the 't-agreement', the greater the likelihood that issue linkage be adopted.

Notice that these conditions neglect the likely increase of transaction costs when negotiating on two linked issues. However, introducing transaction costs would be trivial. They would simply be added to the right-hand side of conditions (3.12), (3.9), (3.13) and (3.10).

Finally, let us note that all equilibrium conditions become less restrictive 
in the presence of majority voting and when the degree of excludability of technological benefits is high ( $\gamma$ is large).

\section{NOTES}

The authors are grateful to two anonymous referees, Scott Barrett, Sergio Currarini, Domenico Siniscalco and to the participants at the Sixth Coalition Theory Workshop held in Louvain and at the Second World Congress of Environmental Economists held in Monterey for helpful comments and suggestions. Corresponding author: Carlo Carraro, Department of Economics, University of Venice, San Giobbe 873, 30121, Venice, Italy. Fax: +39041 2349176. E-mail: ccarraro@unive.it.

1. See Carraro and Marchiori (2002) for an explanation of this and the following assumptions.

2. In the case of symmetric countries, this condition is fairly trivial: it simply means that a country's choice must be rational and that, if a coalition is profitable for one country, it is profitable for all other ones.

3. The extension of our results to the case in which first-stage decisions are taken with majority voting is straightforward.

4. Notice that, when $\gamma>\gamma^{\circ}$, all coalitions $c_{t}$ where $2 \leq c_{t} \leq n$ satisfy the internal stability condition (3.2a), but not the external stability condition (3.2b). In this case, all players want to join the coalition. Hence, we assume that the equilibrium is achieved when $c_{t}=n$.

5. A similar result is also obtained in Alesina et al. (2001).

\section{REFERENCES}

Alesina, A., I. Angeloni and F. Etro (2001), 'The political economy of unions', NBER Working Paper, December 2001.

Barrett, S. (1994), 'Self-enforcing international environmental agreements', Oxford Economic Papers, 46, 878-94.

Barrett, S. (1995), 'Trade restrictions in international environmental agreements', London Business School.

Barrett, S. (1997), 'Towards a Theory of International Cooperation', in C. Carraro and D. Siniscalco (eds), New Directions in the Economic Theory of the Environment, Cambridge: Cambridge University Press.

Bloch, F. (1997), 'Noncooperative models of coalition formation in games with spillovers', in C. Carraro and D. Siniscalco (eds), New Directions in the Economic Theory of the Environment, Cambridge: Cambridge University Press.

Buchner, B., C. Carraro, I. Cersosimo and C. Marchiori (2002) 'Back to Kyoto? US participation and the linkage between R\&D and climate cooperation', FEEM Working Paper no. 22.02, Milan.

Carraro, C. (1998), 'Environmental conflict, bargaining and cooperation', in J. van den Bergh, Handbook of Natural Resources and the Environment, Cheltenham: Edward Elgar.

Carraro, C. (2001), 'Institution design for managing global commons', paper presented at the Fourth FEEM-IDEI-INRA Conference on Energy and Environmental Economics, Toulouse, 3-4 May, 2001 and at the International Conference 'Game Practice and the Environment', Alessandria, 12-13 April 2002. 
Carraro, C. and C. Marchiori (2002), 'Stable coalitions', in C. Carraro (ed.), The Endogenous Formation of Economic Coalitions, Cheltenham: Edward Elgar.

Carraro, C. and D. Siniscalco (1993), 'Strategies for the international protection of the environment', Journal of Public Economics, 52, 309-28.

Carraro, C. and D. Siniscalco (1995), 'Policy coordination for sustainability: commitments, transfers, and linked negotiations', in I. Goldin and A. Winters (eds), The Economics of Sustainable Development, Cambridge: Cambridge University Press.

Carraro, C. and D. Siniscalco (1997), 'R\&D cooperation and the stability of international environmental agreements', in C. Carraro (ed), International Environmental Agreements: Strategic Policy Issues, Cheltenham: Edward Elgar.

Cesar, H. and A. De Zeeuw (1996), 'Issue linkage in global environmental problems', in A. Xepapadeas (ed.), Economic Policy for the Environment and Natural Resources, Cheltenham: Edward Elgar.

Folmer, H., P. van Mouche and S. Ragland (1993), 'Interconnected games and international environmental problems', Environmental Resource Economics, 3, 313-35.

Heal, G. (1994), 'The formation of environmental coalitions', in C. Carraro (ed.), Trade, Innovation, Environment, Dordrecht: Kluwer Academic Publisher.

Hoel, M. (1991), 'Global environmental problems: the effects of unilateral actions taken by one country', Journal of Environmental Economics and Management, 20 (1), 55-70.

Hoel, M. (1992), 'International environmental conventions: the case of uniform reductions of emissions', Environmental and Resource Economics, 2, 141-59.

Katsoulacos, Y. (1997), 'R\&D spillovers, R\&D cooperation, innovation and international environmental agreements', in C. Carraro (ed.), International Environmental Agreements: Strategic Policy Issues, Cheltenham: Edward Elgar.

Konishi, H., M. Le Breton and S. Weber (1997), 'Stable coalition structures for the provision of public goods', in C. Carraro and D. Siniscalco (eds), New Directions in the Economic Theory of the Environment, Cambridge: Cambridge University Press.

Mohr, E. (1995), 'International environmental permit trade and debt: the consequences of country sovereignty and cross-default policies', Review of International Economics, 3, 1-19.

Mohr, E. and J.P. Thomas (1998), 'Pooling sovereign risks: the case of environmental treaties and international debt', Journal of Development Economics, 55, 173-90.

Ray, D. and R. Vohra (1996), 'A theory of endogenous coalition structure', mimeo, Department of Economics, Brown University and Boston University.

Ray, D. and R. Vohra (1997), 'Equilibrium binding agreements', Journal of Economic Theory, 73, 30-78.

Sebenius J.K. (1983), 'Negotiation arithmetic: adding and subtracting issues and parties', International Organisation, 37(2), 281-316.

Tollison, R.D. and T.D. Willett (1979), 'An economic theory of mutually advantageous issue linkages in international negotiations', International Organisation, 33(4), 425-49.

Yi, S. (1997), 'Stable coalition structures with externalities', Games and Economic Behaviour, 20, 201-23. 